\title{
CTD data from casts before and after larval vertical distribution sampling from R/V C-Hawk day cruises in the Eastern Gulf of Maine from 2012 to 2014
}

Website: https://www.bco-dmo.org/dataset/783736

Data Type: Cruise Results

Version: 1

Version Date: 2019-12-30

\section{Project}

" Intertidal community assembly and dynamics: Integrating broad-scale regional variation in environmental forcing and benthic-pelagic coupling (GOMEPRO)

\begin{tabular}{|l|l|l|}
\hline Contributors & Affiliation & Role \\
\hline Yund, Philip & $\begin{array}{l}\text { Downeast Institute for Applied Marine Research and } \\
\text { Education (DEI) }\end{array}$ & $\begin{array}{l}\text { Principal } \\
\text { Investigator }\end{array}$ \\
\hline York, Amber & $\begin{array}{l}\text { Woods Hole Oceanographic Institution (WHOI BCO- } \\
\text { DMO) }\end{array}$ & $\begin{array}{l}\text { BCO-DMO Data } \\
\text { Manager }\end{array}$ \\
\hline
\end{tabular}

\section{Abstract}

CTD data from casts before and after larval vertical distribution sampling from R/V C-Hawk day cruises in the Eastern Gulf of Maine from 2012 to 2014.

\section{Table of Contents}

- Coverage

- Dataset Description

- Acquisition Description

- Processing Description

- Related Publications

- Parameters

- Deployments

- Project Information

- Funding 


\section{Dataset Description}

These data were presented in Weinstock et al., 2018 (see Fig 1 and 2). Only downcast density data were analyzed and presented in Weinstock et al., 2018. Water density data were converted to \% of water column maximum in Figure 2 of Weinstock et al., 2018.

These data are available in two formats. The version in the BCO-DMO data system contains data from all casts concatenated together with added columns cast_name, Cast_time_UTC, start_latitude, start_longitude, end_latitude, and end_latitude which was originally contained in comment and header lines in 35 cast csv files. The 35 individual cast csv files are available in the "Data Files" section as CTD.zip: "CTD csv files with seabird headers."

Related Datasets: CTD casts were conducted immediately before and after the associated larval vertical distribution sampling (separate dataset description) and on both flood and ebb tides.

* CTD cast log for mussel study: https://www.bco-dmo.org/dataset/783749

* Mussel Larvae Vertical Distribution: https://www.bco-dmo.org/dataset/783755

\section{Acquisition Description}

Conductivity, temperature, and depth were sampled via an instrument cast from a small boat. Casts were conducted immediately before and after the associated larval vertical distribution sampling (see Mussel Larvae Vertical Distribution https://www.bco-dmo.org/dataset/783755) and on both flood and ebb tides.

See Weinstock et al., 2018, for more methodology details.

Problem report:

The second cast data for the flood tide on $7 / 31 / 13$ are missing.

\section{Processing Description}

BCO-DMO Data Manager Processing Notes:

* 35 csv files for each cast combined into one tabular dataset. "cast_name" column added which contains information in the original filenames which included "mm_dd_yy_tidephase_cast.csv" 
* The 35 original csv files submitted to BCO-DMO were bundled into CTD.zip and is available to download in the "Data Files" section as "CTD csv files with seabird headers." The only change made to these files was to remove blank rows that were in-between every data and header row in a subset of the 35 files.

* added a conventional header with dataset name, PI name, version date

* modified parameter names to conform with BCO-DMO naming conventions (spaces, + , and changed to underscores). Units in parentheses removed and added to Parameter Description metadata section.

* blank values in this dataset are displayed as "nd" for "no data." nd is the default missing data identifier in the BCO-DMO system.

* Cast timestamp and start/end latitude and longitudes added to this dataset from parsed information contained in comment and header lines in the originally submitted cast csv files. Other information parsed from these comment lines was turned into a second tabular dataset "CTD cast log" (https://www.bco-dmo.org/dataset/783749).

* Data sorted by Cast_time_UTC, Time, Depth columns

[ table of contents $\mid$ back to top ]

\section{Related Publications}

Weinstock, J. B., Morello, S. L., Conlon, L. M., Xue, H., \& Yund, P. O. (2018). Tidal shifts in the vertical distribution of bivalve larvae: Vertical advection vs. active behavior. Limnology and Oceanography, 63(6), 2681-2694. doi:10.1002/lno.10968

[ table of contents $\mid$ back to top ]

\section{Parameters}

\begin{tabular}{|l|l|l|}
\hline Parameter & Description & Units \\
\hline cast_name & $\begin{array}{l}\text { Cast identifier. Contains cast date (in format } \\
\text { mm_dd_yy), tidal phase (e.g. Ebb) and site identifier } \\
\text { (e.g. MB2) where more than one cast was conducted } \\
\text { during o mm_dd_yy_tidephase_cast }\end{array}$ & unitless \\
\hline Pressure & Pressure & $\begin{array}{l}\text { Decibars } \\
\text { (dbar) }\end{array}$ \\
\hline Depth & Depth & Meters (m) \\
\hline & & \\
\hline
\end{tabular}




\begin{tabular}{|c|c|c|}
\hline Density & Density & $\begin{array}{l}\text { Kilograms per } \\
\text { Cubic Meter } \\
\left(\mathrm{kg} / \mathrm{m}^{\wedge} 3\right)\end{array}$ \\
\hline Conductivity & Conductivity & $\begin{array}{l}\text { MicroSiemens } \\
\text { per } \\
\text { Centimeter } \\
\text { (uS/cm) }\end{array}$ \\
\hline Temperature & Temperature & Celsius (C) \\
\hline Specific_conductance & Specific conductance & $\begin{array}{l}\text { MicroSiemens } \\
\text { per } \\
\text { Centimeter } \\
\text { (uS/cm) }\end{array}$ \\
\hline Salinity & Salinity & $\begin{array}{l}\text { Practical } \\
\text { Salinity Scale }\end{array}$ \\
\hline Sound_velocity & Sound velocity & $\begin{array}{l}\text { Meters per } \\
\text { Second }(\mathrm{m} / \mathrm{s})\end{array}$ \\
\hline Time & Seconds elapsed from the start of the cast. & seconds (s) \\
\hline Cast_time_UTC & $\begin{array}{l}\text { Cast date and time (UTC) in ISO } 8601 \text { format yyyy- } \\
\text { mm-ddTHH:MM:SSZ }\end{array}$ & unitless \\
\hline Start_latitude & Cast start latitiude & $\begin{array}{l}\text { Decimal } \\
\text { degrees }\end{array}$ \\
\hline Start_longitude & Cast start longitude & $\begin{array}{l}\text { Decimal } \\
\text { degrees }\end{array}$ \\
\hline End_latitude & Cast end latitiude & $\begin{array}{l}\text { Decimal } \\
\text { degrees }\end{array}$ \\
\hline End_longitude & Cast end longitude & $\begin{array}{l}\text { Decimal } \\
\text { degrees }\end{array}$ \\
\hline
\end{tabular}

[ table of contents | back to top ]

\section{Deployments}

\section{Yund_GoME}




\begin{tabular}{|l|l|}
\hline Website & https://www.bco-dmo.org/deployment/699509 \\
\hline Platform & R/V C-HAWK \\
\hline Start Date & $2012-08-01$ \\
\hline End Date & $2016-07-29$ \\
\hline Description & $\begin{array}{l}\text { The C-Hawk is a } 22 \text { ft. fiberglass modified V-hull. These were multiple single- } \\
\text { day deployments for GOMEPRO project. Eastern Gulf of Maine Sampled with } \\
\text { single-day cruises on: 8/1/12 8/16/12 8/22/12 } \quad 7 / 31 / 13 \quad 7 / 22 / 14 \quad 8 / 5 / 14 \\
8 / 6 / 14 \quad 8 / 14\end{array}$ \\
& $\begin{array}{l}\text { Acquisition Description } \\
\text { Date Site 8/1/12 MB1 8/16/12 MB1 \& MB2 8/22/12 WB1 7/31/13 WB2 7/22/14 } \\
\text { WB3 8/5/14 WB3 8/6/14 WB3 8/7/14 WB3 }\end{array}$ \\
\hline
\end{tabular}

[ table of contents $\mid$ back to top ]

\section{Project Information}

\section{Intertidal community assembly and dynamics: Integrating broad-scale regional variation in environmental forcing and benthic-pelagic coupling (GOMEPRO)}

Coverage: Rocky intertidal shores and nearshore coastal waters throughout the Gulf of Maine

Rocky intertidal habitats in the Gulf of Maine (GoM) provide a model system to examine the structure and dynamics of natural communities. Throughout the Gulf of Maine, the same species are often found in these habitats but community structure, dynamics and productivity differ markedly among 3 distinct regions (southern, central and northern GoM). Past influential work, conducted primarily in the southern and central GoM, focused on the local processes driving intertidal community structure but produced very different conceptual models of how these communities are structured. This project examines whether regional differences in rocky shore community processes are driven by differences in recruitment that are shaped by regional variation in temperature and food availability and nearshore coastal oceanography. This project will improve the understanding of how large-scale environmental forces interact with local processes to control the distribution of species and the structure and dynamics of these communities. Understanding the interaction between processes operating at different scales is fundamentally important to developing more reliable models that can be used to predict community dynamics. In addition, data resulting from this project will have important 
implications for regional dynamics in commercially important species and for ecosystem and fisheries management within the GoM. The overarching hypothesis of this project is that regional differences in community-level processes are driven by very different patterns of population connectivity and recruitment in a few key species, and that these differences are ultimately caused by regional variation in temperature and food availability and mediated by physical larval transport processes. Hence, the project will test the following hypotheses with manipulative field experiments, field sampling, connectivity estimates, and integrative modeling: 1) Locally-dispersing species dominate dynamics in regions with a net export of planktonic larvae (Northern GoM), while species with planktonic larvae dominate the dynamics in regions with high settlement and extensive connectivity among populations (Southern GoM).

2) Settlement density of species with planktonic larvae increases from northern to southern regions in accord with regional variation in food availability. 3) Population connectivity varies greatly among regions, with regions differing in the degree to which they are self-seeded or serve as larval sources vs. sinks; self-seeding leads to relatively localized population dynamics in the middle portion of the GoM. 4) Patterns of population connectivity are driven by physical transport processes and can be represented by coupling basic larval behavior models with circulation models. At 18 different sites in the GoM across $\sim 600 \mathrm{~km}$, surveys will evaluate variation in recruitment, food availability and secondary productivity and experiments will assess community processes in wave-exposed and sheltered habitats. We will use hydrographic, current profile, and larval vertical distribution surveys to collect data for coupled larval/circulation models. Population connectivity will be both modeled and empirically evaluated (for one species) using elemental fingerprinting. A spatially explicit metacommunity model will integrate across all project components and test the relative importance of regional and local processes in controlling community organization and dynamics.

[ table of contents $\mid$ back to top ]

\section{Funding}

\begin{tabular}{|l|l|}
\hline Funding Source & Award \\
\hline NSF Division of Ocean Sciences (NSF OCE) & OCE-1458188 \\
\hline
\end{tabular}

[ table of contents $\mid$ back to top ] 